\title{
A EDUCAÇÃO A PARTIR DAS VOZES DA JUVENTUDE CATARINENSE
}

\author{
CARRER, Davi \\ COSTA, Marli de Oliveira
}

\begin{abstract}
Resumo
Esse artigo discute o trabalho realizado pelo Instituto Catarinense da Juventude (ICJ) com uma parcela da juventude catarinense. O objetivo do estudo é relacionar o processo de escuta dos jovens, pelos pesquisadores do ICJ, no que diz respeito ao que eles pensam acerca da educação. A metodologia utilizada foi a análise documental do livro "Vozes da juventude catarinense: rodas de conversa". Como categorias de análise foram utilizados: conceito de juventude e Roda de Conversa. Além dessas categorias, o livro Retratos da Juventude Brasileira permitiu realizar comparações sobre a pesquisa do ICJ e a pesquisa de Abramo e Branco (2005). A juventude de Santa Catarina na pesquisa do ICJ (2014) falou de suas ansiedades, desejos e sonhos diante da educação escolar e não descolou o papel da educação do mundo do trabalho.
\end{abstract}

Palavras-chave: Juventude catarinense. Educação. Jovens. Escuta. Instituto Catarinense de Juventude.

\section{INTRODUÇÃO}

Escutar os jovens, as juventudes, é uma ação que vai na contramão do tradicional, afinal, conforme traz o Instituto Catarinense de Juventude (2014, p. 7), asociedade está acostumada a falar para a juventude, apontando seus erros, direcionando-os e enquadrando-os ao mundo dos adultos. Assim, registrar as vozes da "juventude possibilita aprofundar o conhecimento sobre sua realidade, valorizar seu jeito e construir caminhos para a garantia e efetivação de seus direitos".

Este artigo é resultado dessa provocação, buscando ajudar na transformaçãoda realidade da juventude, a partir da sua voz e não da sociedade adulta. Nakano e Almeida (2007, p. 1089), ao comentar estudo parecido, lembram que a possibilidade de fazer tal leitura é recente, sendo inimaginável conceber e fazer um estudo como esse há algumas décadas atrás: "No passado, os jovens eram compreendidos como indivíduos a serem socializados pelas gerações adultas, de cima para baixo, pelas instituições que legitimavam para contribuir nesse processo de reprodução social".

Criar Educação, Criciúma, v. 6, no1, janeiro/junho 2017.- PPGE - UNESC 
Em 2014 participei do Projeto "ConversAção", do ICJ, que deu origem ao livro "Vozes da juventude catarinense: rodas de conversa". A obra é "fruto de muitas vozes, cheias de gritos, alegrias e medos, sistematizadas por quem teve ousadia e coragem de fazer o processo de escuta: o Instituto Catarinense de Juventude" (ICJ, 2014, p. 6).

Com algumas exceções, as escutas, que deram origem ao livro, foram realizadas em espaços escolares. Por isso, dessa pesquisasurgiu a indagação: 0 que os jovens catarinenses pensam sobre a educação, a escola...? Este artigo relaciona a escuta sem interferência direta dos adultos às reflexões desses jovens com a temática Educação, trazendo presente cada momento, cada fala que era dita e abordava o assunto ao longo das páginas do livro.

No decorrer desse estudo apresentoum pouco da obra do ICJ e sua metodologia. Abordo o conceito de juventudes. E, na sequencia, analisoas vozes jovens catarinenses sobre o tema educação, trabalhando com as questões: "Como é ser jovem hoje", "Que espaços têm os jovens na comunidade" e "A sociedade acredita na juventude?".

$E$, se o ato de dar voz aos jovens, oferece a oportunidade da efetivação dos seus direitos, destacar e analisar os dados sobre Educação que o livro traz se torna fundamental.Nakano e Almeida (2007, p. 1088), quando analisam dados sobre juventude salientam a importância desses materiais para pensar questões relacionadas à qualidade da educação:

\begin{abstract}
A capacidade que têm muitos jovens de olhar e analisar o processo de escolarização toca a muitos de nos, agentes públicos, formuladores e gestores de políticas, atores da sociedade civil, pesquisadores e professores, porque os reconhecemos como sujeitos de direitos, com necessidades e interesses particulares. Nos dias atuais, o reconhecimento dos jovens como titulares de direitos e a busca de interlocução com eles é absolutamente fundamental, especialmente para aqueles que desejam ampliar os espaços democráticos e o desenvolvimento em nossa sociedade, enfrentando os dilemas da qualidade da educação escolar pública no Brasil.
\end{abstract}

Nesse sentido, compreendo os jovens como capazes de pensar e refletir acerca de seus processos educacionais em escolas. $E$ por isso faço as analises a seguir, começando sobre como o ICJ os ouviu? 


\section{CRIAR EDUCAÇÃO \\ Revista do Programa de Pós-Graduação em Educação - UNESC}

\section{LIVRO E A PESQUISA}

O livro "Vozes da juventude catarinense: rodas de conversa" traz uma escuta qualificadade adolescentes e jovens, a partir de 45 Rodas de Conversa, em 15 cidades catarinenses: Abelardo Luz, Blumenau, Chapecó, Cocal do Sul, Criciúma, Entre Rios, Itajaí, Joaçaba, Joinville, Lages, Monte Carlo, Navegantes, Ouro, São José e Xanxerê."Em cada município foram feitas três Rodas, com grupos de aproximadamente 25 participantes, utilizando uma metodologia indutiva que possibilitou o diálogo a partir dos jovens, dando-Ihes voz" (ICJ, 2014, p. 6).

\subsection{Um exercício de escuta}

A maioria das Rodas de Conversa foi realizada em escolas públicas, possibilitando a reunião de faixas etárias semelhantes. Conforme o ICJ (2014, p. 7), a obra buscou reunir aspectos recorrentes nas falas dos jovens. Com isso "esperase provocar reflexões e articulação para o fortalecimento das Políticas Públicas de Juventude".

Para sustentar a ideia de que essas escutas são qualificadas, elas foram organizadas a partir de um referencial. O ICJ buscou em Teixeira, Silva e Alves (2010) a metodologia que aplicaram no livro "Rodas de Conversa - A juventude quer viver", do Centro de Juventude "Cajueiro", de Goiás.Os autores explicam que as rodas são espaços privilegiados "de interlocução com os sujeitos da pesquisa, uma vez que a dinâmica que se constitui, no decorrer de sua execução, possibilita que as pessoas envolvidas falem, escutem, discutam e exponham sua opinião a respeito dos temas em debate" (p.54). São (p.56)

[...] pessoas interagindo a espera para falar, o ouvir o outro. Nesse sentido, ressalta-se que o movimento proporcionado pela Roda é muito importante na medida em que abre um espaço privilegiado aos/às participantes para que exponham suas ideias,ocorrendo uma rica experiência de escuta, de debate e, particularmente, de respeito às diferentes opiniões. Daí que a Roda torna-se uma rica experiência.

Após identificar a importância da escuta é necessário optar por uma metodologia que garanta a ressonância das vozes dos jovens.

\subsection{Metodologia}

Criar Educação, Criciúma, v. 6, no1, janeiro/junho 2017.- PPGE - UNESC 


\section{CRIAR EDUCAÇÃO}

Revista do Programa de Pós-Graduação em Educação - UNESC

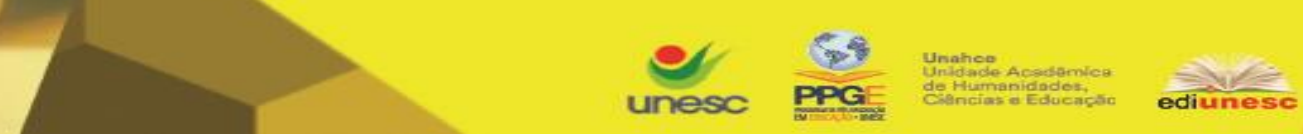

"Escutar, mais do que falar, é sempre um desafio para quem trabalha com juventude", relata o ICJ (2014, p. 8). Por isso, o planejamento para realizar as escutas foi focado no "escutar com qualidade", a partir de uma metodologia inovadora, sistematizada no livro Teixeira, Silva e Alves. Os referidos autores explicam que "a opção metodológica feita foi a pesquisa-ação, definida, basicamente, pela reciprocidade existente entre os atores da pesquisa, no caso, os/as jovens"(2010, p.53).

É importante que se reconheça a pesquisa-ação como um dos inúmeros tipos de investigação-ação, que é um termo genérico para qualquer processo que siga um ciclo no qual se aprimora a prática pela oscilação sistemática entre agir no campo da prática e investigar a respeito dela. Planeja-se, implementa-se, descreve-se e avalia-se uma mudança para a melhora da prática, aprendendo mais no correr do processo, tanto a respeito da prática quando da própria investigação. (TRIPP, 2005, p.446, apud TEIXEIRA, SILVA E ALVES, 2010, p. 53-54)

E, a partir desta linha metodológica, foram preparadas as Rodas de Conversa desenvolvidas pelo ICJ. Nelas, os temas foram articulados entre si, o que possibilitou formar o caminho, pois se:

[...] começa o trajeto olhando cada jovem em sua individualidade; em seguida os grupos que participa e o lugar em que vive; até chegar ao ponto em que se refletem questões mais abrangentes da sociedade brasileira e sua relação com a juventude. (ICJ, 2014, p. 14).

A metodologia previa reunir jovens em grupos, e, em cada um, realizar três Rodas de Conversa com as seguintes temáticas:

Imagem 1 - Temáticas aplicadas nas Rodas de Conversa 

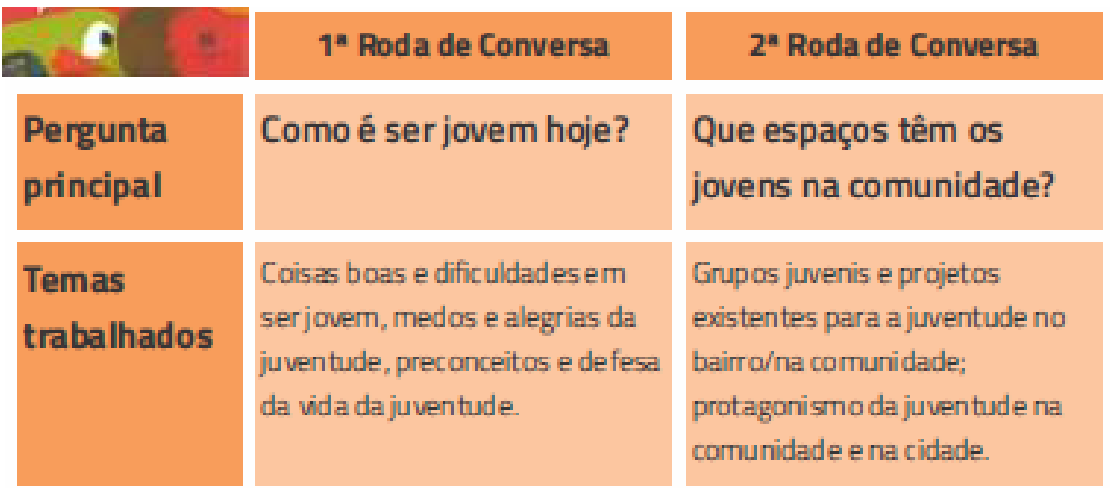

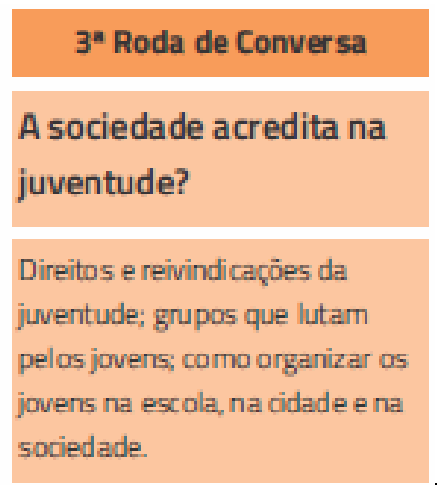

Fonte - Instituto Catarinense de Juventude (2014, p. 8)

A partir dessa proposta os jovens puderam falar e conversar entre si. Conforme relata o ICJ (2014, p. 53), eles se expressaram "por meio das suas falas, do seu silêncio, do movimento de seus corpos, do riso, da timidez, da euforia, das suas diferentes formas de expressão". Através das experiências de escutas foi possível perceber que os jovens falavam "dos sonhos, dos direitos que desejam que sejam garantidos, das violências e dos preconceitos que sofrem, de aspectos positivos e negativos de ser jovem" e muito mais. Todo esse processo de escuta foi realizado sem intervenção dos articuladores das Rodas de Conversa. Eles estavam lá apenas para articular o dialogo, sem colocar opinião sobre o que era dito pelas juventudes.

Desta maneira, tanto as críticas quanto os resultados obtidos partiram deles/as, demonstrando que esta categoria, ao contrário do que muitos dizem, sabe o que ser, o que é melhor para eles/elas, percebe os problemas que estão à sua volta, tem pontos de vista sobre as diferentes questões sociais, culturais, políticas e econômicas que envolvem a sociedade e apontam demandas que envolvem a educação, a saúde, o emprego, a violência entre outros. (TEIXEIRA, SILVA E ALVES, 2010, p.54).

Em todo este processo de Rodas de Conversa foram envolvidos 306 jovens, com idade de 15 a 20 anos - a maioria entre 16 e 17 anos. 


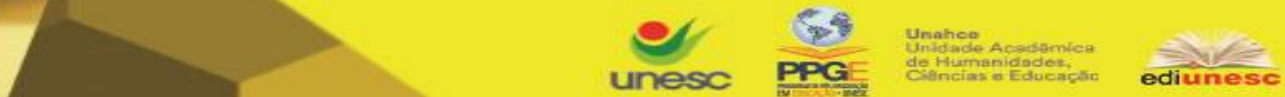

Esse estudo, em questão, analisa a voz dos participantes nas Rodas de Conversa. Em sua obra, o ICJ (2014) traz dados dos jovens catarinenses que tiveram voz nesses espaços, como:

a) $63 \%$ declararam ser de etnia branca; $14 \%$ parda; $12 \%$ indígena; $11 \%$ negra;

b) $68 \%$ possuem experiência de trabalho; $53 \%$ estão trabalhando atualmente.

Para abordar suas vozes além das discussões metodológicas acerca da Roda de Conversa é necessário compreender o conceito de juventudes.

\section{JUVENTUDES}

Para continuar a discutir sobre o que a juventude catarinense dizer sobre a educaçãoé preciso saber quem são estes jovens. Porém, conforme traz Barbosa (2014, p. 2), "Falar sobre os jovens ou tentar defini-los é desafiador. A juventude, uma suposta fase de transição entre a infância e a vida adulta, vem assinalada de complexidades". Para Frigotto (2004, p. 180-181), essa complexidade:

Tem início com a dificuldade de se ter um conceito unívoco de juventude, por razões tanto históricas quando sociais e culturais. Assim, é necessário, de imediato, não o tomar de forma rígida. Mais adequado seria, talvez, falar, como vários autores indicam, em juventudes, especialmente se tomarmos um recorte de classe social. Ao optarmos por essa compreensão, poderemos levar em conta particularidades e até aspectos singulares sem cair numa perspectiva atomizada.

Já lulianelli (2003, p. 60) descreve "que juventude é um segmento social definido culturalmente". Ele considera que para "cada sociedade há situações diferentes para este mesmo grupo social".

Nesse sentido não pode-se falar de "juventude", mas de juventudes, pois o tempo para a essa fase da vida depende da classe social, do gênero, da etnia e de outros elementos culturais.

O ICJ (2014) caracteriza a juventude pelo seu caráter de condição provisória, em processo de transição da infância à vida adulta, sendo um contingente de 51 milhões de brasileiros, levando em conta a faixa etária de 15 a 29 anos, segundo o IBGE (2010). Porém, Barbosa (2014, p. 2) lembra que "o conceito de juventude é 
elástico e ultrapassa marcações etárias ou critérios biológicos, incorporando outras dimensões". Para ela, e autores dos Estudos Culturais em Educação, a juventude é uma construção sociocultural: "tem a ver com as experiências vivenciadas pelos sujeitos e como estas são significadas e narradas em cada contexto históricossocial".

E não se vai negar aqui a definição de que o próprio jovem catarinense dá sobre juventude. Para eles:

É uma fase de preparação para a vida adulta: de responsabilidades, de ajudar em casa, trabalhar, estudar, pensar no futuro, fazer escolhas, de mudanças e de correr atrás de sonhos. Ser jovem também é ser diferente, ser original, é descobrir coisas novas, ter a mente aberta, conhecer pessoas, aprender o que é certo e errado. É ter a capacidade de fazer muitas coisas ao mesmo tempo e de falar o que pensa. É estar conectado às tecnologias. É ser livre.(INSTITUTO CATARINENSE DE JUVENTUDE, 2014, p. 17).

Lulianelli (2003, p. 61) lembra que:

Os jovens são considerados delinquentes, sobretudo, quando não estão integrados aos sistemas educacionais, aos mecanismos de inserção no mercado de trabalho e às estratégias públicas de esporte, cultura e lazer. [...] Os analistas deixam a juventude em duas situações incômodas: delinqüentes e/ou responsáveis pelo destino do gênero humano.

A partir de cada Roda, os jovens foram se soltando, fazendo se ouvir e com a esperança de que suas vozes ecoassem. "Muitas vozes vieram à tona a partir destas Rodas. O desejo é fazê-las ressoar e serem sinais de transformação da realidade das juventudes catarinenses" (ICJ, 2014, p. 60).

E o que esses jovens disseram sobre a educação?

\section{A EDUCAÇÃO A PARTIR DAS VOZESDOS JOVENS}

O livro "Vozes da juventude catarinense: rodas de conversa" abordou inúmeros assuntos nas Rodas de Conversa. Na primeira Roda foi discutido "Como é ser jovem hoje?", os jovens falaram sobre coisas boas, dificuldades, medos, alegrias, preconceitos e defesa da vida da juventude. Na segunda Roda, ao tratar "Que espaços têm os jovens na comunidade?", eles conversaram sobre grupos e projetos que existem para os jovens no bairro/comunidade, protagonismo na 


\section{Unesc PPGE}

comunidade/cidade. Na terceira Roda, com a pergunta "A sociedade acredita na juventude?", os assuntos foram direitos, reinvindicações, grupos que lutam pelos jovens, como se organizar os jovens na escola/cidade/sociedade.

Esse estudo buscou focar apenas uma temática, que apareceu na fala dos jovens, desde a primeira pergunta até a última Roda, que foi Educação, no entanto é necessário passar pelos outros temas para compreender o lugar da educação em suas vozes.

\subsection{Como é ser jovem hoje?}

Na primeira Roda, quando falavam sobre "Como é ser jovem hoje?", coisas boas, dificuldades, medos, alegrias, preconceitos..., deixaram evidente que estudar faz parte dessa fase de transição, como se fosse uma preparação para a vida adulta. Nakano e Almeida (2007) lembram que os jovens brasileiros têm seguido os percursos institucionais clássicos, como a escola. Nem todos aderem, mas não há recusa.

A ideia da educação escolaré vista como uma das alegrias, como traz o ICJ (2014, p. 18): "ter tempo para decidir o que vai fazer no futuro". Abramo e Branco (2005), na obra Retratos da Juventude Brasileira, apresentam que essa é também uma realidade nacional: "74\% dizem que há mais coisas boas do que ruins em ser jovem" (p. 55).

A escola como criação da sociedade moderna buscou preparar crianças e jovens para o trabalho. Assim, a função social da escola não percebe as crianças e os jovens na fase da vida em que estão, e sim naquilo que serão. No entanto, uma das falas dos jovens entrevistados pelo ICJ percebe a escola para além dessa função.

E se um dia, por um acaso, eu acabar todo o meu estudo - até porque eu não acho que estudo seja só pra ganhar dinheiro, né, eu sou totalmente contra essa ideia, pra mim isso daí é segundo plano, o que você ganha na escola, com o conhecimento, com a sabedoria é muito maior do que o dinheiro, mas pro adulto é simplesmente isso, você tem que estudar pra ganhar dinheiro, - e se você não ganha dinheiro, mesmo você tendo estudado muito, parece que tudo aquilo foi jogado fora. $E$ o jovem cresce com essa questão na cabeça, o medo de não satisfazer financeiramente a família. De não ser, ter sido diferente, de não ter sido um médico, um doutor, um advogado. Aí a família fica decepcionada (ICJ, 2014. p. 20) 
No entanto, percebe-se nessa fala também um certo"medo do futuro", que parece incerto, diante das impossibilidade em realizar seus sonhos ou de seus pais, ou ser aquilo que a sociedadeespera deles, percebi que essas falas aparecem com certa frequência.

Nesse sentido, Silva e Oliveira (2007, p. 32) nos lembram que a organização da escola tem como foco o mundo do trabalho. "A escola seria a promessa de integração. Por isso, o trabalho é o terceiro termo da tríade compondo com os outros dois juventude-educação".E o medo anunciado pelos jovens vem nesta mesma relação, também carregado de preconceitos, como trazem:

a) "achar que muitos não têm futuro, só por olhar pela aparência. Que na escola, por exemplo, de tanto falar que não tem futuro muitos desistem" (ICJ, 2014. p. 24);

b) "O poder só vê que o lugar do jovem é na escola. Não podemos fazer nada diferente. Só de andar na rua já somos discriminados. O poder não está nem aí pra quem tem poder aquisitivo baixo. Em Jurerê Internacional eles estão fumando e não acontece nada. Você esta lá na frente da escola só conversando e já vem perguntando o que estou fazendo"(ICJ, 2014. p. 27).

São medos e alegrias que parecem se contradizer, mas na verdade refletem uma realidade juvenil, ou melhor, as realidades juvenis, poisnão está presente apenas nas vozes catarinenses.Abramo e Branco (2005) refletem sobre isso e revelam que muitos dos estudos recentes tratam do assunto e, nessa fase de transição para a vida adulta, os jovens buscam refletir uma imagem que a sociedade impõem como de bem-sucedido: "ter sido um médico, um doutor, um advogado" (ICJ, 2014, p.20). E, embora o dado a seguir do estudo nacional de Abramo e Branco, seja relacionado ao trabalho, a tríade de Silva e Oliveira acaba estando sempre presente:

Para $39 \%$ dos jovens, a palavra que mais se aproxima do que pensam sobre trabalho é necessidade, mas houve índices significativos de escolha também para as outras três palavras propostas pelos pesquisadores (independência, 26\%; crescimento, 22\%, auto-realização, 11\%); apenas exploração teve uma escolha residual (1\%).( autor2005, p. 53)

Criar Educação, Criciúma, v. 6, no1, janeiro/junho 2017.- PPGE - UNESC 


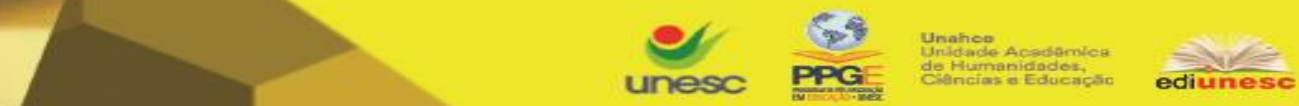

Dados que demonstram que a preocupação de satisfazer os outros ou de quebrar essa dependência do outro é muito marcante não apenas no jovem catarinense, mas no jovem brasileiro.

\subsection{Que espaços têm os jovens na comunidade}

Quando falavam sobre "Que espaços têm os jovens na comunidade?", na segunda Roda, eles trouxeram dados sobre grupos e projetos que existem para os jovens na comunidade, além de conversarem sobre protagonismo.

A obra do ICJ (2014) mostra que os jovens enxergam a escola como um espaço na comunidade, mas não o principal, ficando na quarta posição, conforme traz a imagem 2 - as respostas eram verbais e nem todos responderam, somando, nesta pergunta, 36 respostas dos 306 participantes. Silva e Oliveira (2007, p. 32) lembram que "A lógica da escola é delimitada pelo mundo adulto, mas, em relação ao mundo juvenil que nela se forma, desenvolve-se e se confronta com os padrões adultos".

Imagem 2 - Respostas sobre "Que espaços têm os/as jovens na comunidade/bairro?"

\begin{tabular}{l|l|l|}
\hline Igreja & \multicolumn{1}{c}{8 respostas } \\
\hline Espaços esportivos & 7respostas \\
\hline Não existem espaços & 7 respostas \\
\hline Escola & 5 respostas & \\
\hline Espaços de lazer & 4 respostas & \\
\hline Espaços de luta/transformação social 2 respostas & \\
\hline Espaços ligados a Trabalho/emprego 2 respostas & \\
\hline Espaços culturais 1 resposta &
\end{tabular}

Fonte - Instituto Catarinense de Juventude (2014, p. 34)

Isso refletecomo traz Abramo e Branco (2005), uma realidade nacional, em que vem havendo, cada vez mais, um desinteresse pela escola. $O$ jovem tem se distanciado desse espaço e já não o enxergam como um espaço dele, mas sim como um local que elestêm a obrigação de estar. Acaba sendo, como trouxe anteriormente lulianelli, a questão incomoda do jovem: ser delinquente ou responsável pelo futuro.Reflexo disso é que a escola quase desaparece quando o 


\section{CRIAR EDUCAÇÃO}

Revista do Programa de Pós-Graduação em Educação - UNESC

assunto são grupos juvenis, aparecendo na última posição e citada apenas uma vez, conforme imagem 3:

Imagem 3 - Respostas sobre "Quais os grupos juvenis existentes na comunidade/bairro?"

\begin{tabular}{lr}
\hline Espaços de luta e transformação social & 10 respostas \\
\hline Espaços culturais & 9 respostas \\
\hline Igrejas & 9 respostas \\
\hline Espaços esportivos & 7 respostas \\
\hline Espaços de lazer & 6respostas \\
\hline Escola 1 resposta & \\
\hline
\end{tabular}

Fonte - Instituto Catarinense de Juventude (2014, p. 35)

E os reflexos desse distanciamento com a escola continuam quando os jovens foram questionados sobre projetos existentes para a juventude na sua comunidade. Projetos ligados a escola aparecem em penúltimo lugar, conforme figura 4. Aparece, inclusive, um depoimento de um jovem com descrença sobre a escola: "As escolas muitas vezes conhecem projetos, mas passam longe para não dar trabalho pra eles" (p. 36).

\section{Imagem 4 - Respostas sobre "Quais os projetos existentes para a juventude em sua} comunidade/bairro?"

\begin{tabular}{|l|r|}
\hline Não existem projetos & \\
\hline Projetos culturais & 4 respostas \\
\hline Projetos esportivos & 4 respostas \\
\hline Projetos ligados a igrejas & 3 respostas \\
\hline Projetos de transformação social & 3 respostas \\
\hline Projetos ligados à trabalho/emprego & 3 respostas \\
\hline Projetos ligados à escola 2 respostas & \\
\hline Proj. de lazer 1 resposta & \\
\hline
\end{tabular}

Fonte - Instituto Catarinense de Juventude (2014, p. 36)

Ainda na segunda Roda do ICJ (2014), o espaço escola foi citado na resposta à pergunta "Que ações podemos fazer em defesa da juventude?". Nessa resposta a 
escola é espaço etambém foi dada por apenas um jovem, que disse "Palestras na escola".

\subsection{A sociedade acredita na juventude?}

$\mathrm{Na}$ terceira e última Roda do Instituto Catarinense de Juventude (2014) os jovens falaram sobre "A sociedade acredita na juventude?", conversando sobre direitos, reinvindicações, grupos que lutam pelos jovens, e como se organizam os jovens. Mesmo esta Roda não tratar de sonhos, os jovens os trouxeram, pois eles surgiram como direitos e reinvindicações. E a educação estava presente, quando um jovem falou: "Estudar, ter oportunidade de trabalhar" (p. 45). E isso fica ainda mais evidente quando eles falaram sobre "Quais os direitos da juventude":

O direito a "Educação" lidera, com 17,5\%, seguido de "Esporte, lazer e cultura" e "Saúde", com 15,5\% cada. O direito a "Profissionalização" e ao "Trabalho" vieram depois, com 8,25\% cada, e logo em seguida o direito de "Ir e vir", com 7,2\% das respostas. (autor e ano p. 47)

Percebe-se que, quando os jovens se referem a profissionalização, eles falam de preparação ao mercado de trabalho, que também entra na linha da escola. Como Frigottoreflete ao dizer que isso é uma interiorização de uma lógica de estrutura social e poder: "Trata-se de adquirir o "pacote" de competências que o mercado reconhece como adequadas ao "novo cidadão produtivo".(2004, p. 197)

A Educação continuou a aparecer nas falas sobre "Quais as reinvindicações da juventude": "Aqui, a "Educação" apareceu com 11,9\% das respostas" (ICJ, 2014, p. 48), sendo a segunda resposta mais mencionada.

Os dados do ICJ diferem muito pouco da pesquisa nacional de Abramo e Branco (2005, p. 62), em que "Educação e emprego aparecem praticamente empatados na lista de assuntos que interessam aos jovens, cada um deles citados espontaneamente por mais de um terço da mostra". Na pesquisa do ICJ, educação continua sendo a prioridade, mas trabalho cai.

Os dados também vêm ao encontro ao que Abramo e Branco (2005, p. 109), trazem sobre o tema de maior interesse dos jovens: "educação". A escola, a educação é sim um interesse do jovem brasileiro e catarinense, porem eles não se enxergam nesse atual modelo e por isso "professores e a escola são muito pouco 
citados como possíveis alternativas para diálogos e conversas em torno de assuntos considerados relevantes pelos jovens" (p. 114).

O espaço escolar continua tendo destaque nessa Roda quando o assunto foi "Que grupos lutam pelos jovens". A resposta com mais adeptos foi "Escola", com $17,2 \%$ das falas, sendo que aqui não entrou "Professor", que ficou com 6,9\%. Somados, dariam 24,1\%" (ICJ, 2014, p. 49).

Nesta Roda havia uma pergunta específica: "Como organizar os jovens na escola"?. E“31,6\% dos jovens sugeriram "Envolvendo e conversando"; 21,1\% por meio de"Projetos" e "União", cada; 15,8\% "Conscientizando"; 10,5\% pela "Internet"' (p. 50). Esses números apontam algo importante: os jovens querem se organizar e não serem organizados. Eles respondem pensando em ser os protagonistas, até mesmo nas escolas.

Percebe-se então que os desejos, sonhos e anseios da juventude catarinense não destoam dos jovens brasileiros. O direito à educação e uma escola que leve em conta a fase da vida em que se encontram parece ser almejado pela juventude que mostra entendimento do papel da escola, para além da formação para o mundo do trabalho.

\section{CONCLUSÃO}

Quando iniciei esse estudo, buscava relacionar juventude e educação, relacionando a escuta dos jovens pelo ICJ sem interferência direta de suas vozes com a temática Educação. Porém, ao longo da construção do estudo, ficou evidente que a não inserção de um terceiro elemento era inviável: o trabalho. $E$ isso me fez entender a citação de Silva e Oliveira (2007, p. 32), de que "o trabalho é o terceiro termo da tríade compondo com os outros dois juventude-educação".

Trago isso, pois o presente estudo retrata alguns pontos. Primeiramente essa questão da tríade juventude-trabalho-educação, em que a escola, a educação se dá como uma preparação do jovem a vida adulta, não focado no ser humano, mas sim no trabalhador. E, esse estudo, como confirmaAbramo e Branco (2005), demonstra que a juventude ainda está ligada ao mundo do trabalho. Que a escola ainda está com um olhar voltado para a mão de obra e não para o jovem que está na sua frente. Isso sugere "a necessidade de continuo exame das relações entre escola e trabalho sob o ponto de vista dos jovens" (p. 106). 
No entanto, em uma das falas um jovem diz que a escola também teria outra função. "[...] o que você ganha na escola, com o conhecimento, com a sabedoria é muito maior do que o dinheiro, mas pro adulto é simplesmente isso, você tem que estudar pra ganhar dinheiro" (ICJ, 2014. p. 20).

E esse é outro ponto importante que os jovens trazem: a descrença nos espaço escolaresversus o interesse pela educação. Os jovens não acreditam no que está lá, mas entendem que a educação e o caminho certo, um direito deles. Isso demonstra que mesmo com um modelo antiquado, ainda há crença por parte dos jovens na educação. Realidade que é nacional, afinal, eles "depositam confiança na escola, em relação ao projeto futuro, mas as relações são mais difíceis e tensas com o tempo presente" (ABRAMO, BRANCO, 2005, p.124). E, como lembram Nakano e Almeida (2007), os jovens querem ver a escola como uma experiência, boa de preferencia, e não como uma obrigação, algo compulsório. Os jovens querem ser protagonistas, mesmo quando não entendem esse termo.

O livro do ICJ encerra trazendo algumas recomendações e trago uma que traduz a recomendação desse pesquisador à sociedade: "Reconhecer a juventude não somente como uma fase preparatória à vida adulta, mas com um valor em si mesma" (2014, p. 60).

\section{REFERÊNCIAS}

ABRAMO, Helena Wendel; BRANCO, Pedro Paulo Martoni(Org.). Retratos da juventude brasileira: análises de uma pesquisa nacional. São Paulo: Fundação Perseu Abramo e Instituto Cidadania, 2005.

BARBOSA, Liége Freitas. Jovens e movimentos sociais no Brasil: interrogando significados das manifestações de junto de 2013. In: X AMPED SUL. Caderno de Resumos - online. Florianópolis: UDESC, 2014. Disponível em:

$<$ http://xanpedsul.faed.udesc.br/arq pdf/1800-0.pdf>. Acesso em: 14 nov. 2016.

FRIGOTTO, Gaudêncio. Juventude e educação no Brasil: perplexidades, desafios e perspectivas. In: NOVAES, Regina; VANNUCHI, Paulo (Org.). Juventude e sociedade: Trabalho, Educação, Cultura e Participação. São Paulo: Editora Fundação Perseu Albano e Instituto Cidadania, 2004, p. 180-216.

INSTITUTO CATARINENSE DE JUVENTUDE. Vozes da juventude catarinense: rodas de conversa. Instituto Catarinense de Juventude. Xanxerê: Newsprint, 2014. 


\section{CRIAR EDUCAÇÃO}

Revista do Programa de Pós-Graduação em Educação - UNESC

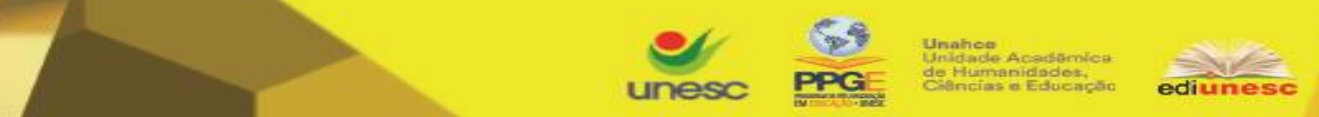

IUANELLI, Jorge Atílio Silva. Juventude: Construindo processos - o protagonismo juvenil. In: FRAGA, Paulo Cesar Pontes; IUANELLI, Jorge Atílio Silva (Org.). Jovens em tempo real. Rio de Janeiro: DP\&A, 2003, p. 54-75.

NAKANO, Marilena; ALMEIDA, Elmir. Reflexões acerca da busca de uma nova qualidade da educação: relações entre juventude, educação e trabalho. Educ. Soc., Campinas, vol. 28, n. 100 - Especial, p. 1085-1104, out. 2007. Disponível em: $<$ http://www.observatoriodoensinomedio.ufpr.br/wpcontent/uploads/2014/02/REFLEXOES-ACERCA-DA-BUSCA-DE-UMA-NOVAQUALIDADE-DA-EDUCACAO.pdf>. Acesso em: 10 jul. 2016.

SILVA, Iliezi Luciana Fiorelli; OLIVEIRA, Rosemary Batista de. Juventudes, educação e trabalho - estudos e políticas públicas em Londrina-PR. In: JEOLÁS, Leila Sollberger; PAULILO, Maria Angela Silveira; CAPELO, Maria Regina Clivati (Orgs.). Juventudes, desigualdades e diversidades. Paraná: Eduel, 2007, p. 2355.

TEIXEIRA, Carmen; SILVA, Lourival Rodrigues; ALVES, Miriam Fábia (Org.). A Juventude quer viver: Condição juvenil e redes de proteção em Goiás. Goiás: Casa da Juventude e PUC de Goiás, 2010. 